\title{
Requirements Gathering Through Focus Groups for a Real Time Emergency Communication System for HAZMAT Incidents (REACH)
}

\author{
Sharon Medcalf, PhD $^{1 *}$, Matthew L. Hale, PhD $^{2}$, Chandran Achutan, PhD, $\mathbf{C I H}^{1}$, Aaron M. Yoder, PhD ${ }^{1}$, Ann Fruhling, \\ PhD $^{1}$, and Stanley W. Shearer, FF/EMT-P ${ }^{3}$ \\ ${ }^{1}$ College of Public Health, University of Nebraska Medical Center, United States. \\ ${ }^{2}$ College of Information Science and Technology, University of Nebraska - Omaha, United States. \\ ${ }^{3}$ Omaha Fire Department, Information Technology Division, United States.
}

\section{Article Details \\ Article Type: Research Article \\ Received date: $10^{\text {th }}$ September, 2021 \\ Accepted date: $17^{\text {th }}$ November, 2021 \\ Published date: $19^{\text {th }}$ November, 2021}

Corresponding Author: Sharon Medcalf, PhD, Assistant Professor, Department of Epidemiology, Center for Biosecurity, Biopreparedness and Emerging Infectious Diseases, College of Public Health, University of Nebraska Medical Center, United States. E-mail: smedcalf@unmc.edu

Citation: Medcalf, S., Hale, M.L., Achutan,C., Yoder, A.M., Fruhling, A., \& Shearer, S.W. (2021). Requirements Gathering Through Focus Groups for a Real Time Emergency Communication System for HAZMAT Incidents (REACH). J Pub Health Issue Pract 5(2): 188. doi: https://doi.org/10.33790/jphip1100188

Copyright: $(22021$, This is an open-access article distributed under the terms of the Creative Commons Attribution License 4.0, which permits unrestricted use, distribution, and reproduction in any medium, provided the original author and source are credited.

\begin{abstract}
During HAZMAT emergencies, first responders are the first to reach the incident site. Over the years, there has been an increase in the number of first responder deaths and heat related illness. Heat-related illnesses are most often studied in outdoor workers and wild land firefighters but occur in a variety of workers across the US. Surveillance programs reported approximately 28,000 HRI hospitalizations between 2001 and 2010. The progression from heat exhaustion to heat stroke can occur rapidly so first responders need warning systems to alert them to the impending health hazards of heat stress. This study works with HAZMAT first responders in Nebraska to explore and assess the status of responder safety in the state and begins with the first responder focus group requirements gathering process. A consensus building process was used for the focus group sessions and yielded thematic areas of health and safety concern. Responder safety was named the most common area of concern and solutions to individual risks were proposed by focus group participants from a local HAZMAT response team. The results of this focus group serve to inform researchers of priorities to consider in the development of responder health monitoring systems and to continue with research in wearable technology for real time health monitoring. Early intervention when monitored responders demonstrate signs of distress ultimately saves lives.
\end{abstract}

Keywords: HAZMAT, First Responder Safety, Heat Stress

\section{Introduction}

According to the U.S. DOT Pipeline and Hazardous Materials Safety Administration (PHMSA), Office of Hazardous Materials Safety (OHMS), hazardous materials traffic in the U.S. now exceeds 800,000 shipments per day [1] which translates to approximately 300 million shipments of hazardous materials and more than 3.1 billion tons of hazardous materials moving across American roads annually. Out of these, 94\% of HAZMAT shipments are moved by trucks [1]. Between 2011 and 2020, there were 153,451 HAZMAT incidents on US highways, with damage totaling over $\$ 600 \mathrm{M}$ [2].

During HAZMAT emergencies, first responders, including fire fighters, police officers, emergency medical service personnel (paramedics), and representatives of the department of environmental quality, are the first to reach the incident site. Over the years, there has been an increase in the number of first responder deaths, which has been a call to action for organizations like the National Fire Protection Association (NFPA) to further study the firefighter problem.

Approximately 100 firefighters die in the line of duty each year and the leading cause is a sudden cardiac event [3]. Experts have long known that excessive heat emergencies can lead to cardiac events. Heat-Related Illness (HRI) is most often studied in outdoor workers and wild land firefighters, but can occur in a variety of workers across the US. CDC's Environmental Public Health Tracking program reported approximately 28,000 HRI hospitalizations between 2001 and 2010 [4].

The progression from heat exhaustion (malaise, headache, nausea) to heat stroke (central nervous system symptoms, cardiac arrhythmias, core body temperature $>40$ degrees Celsius, vital organ damage) can occur rapidly, and the distinction is at times difficult. It is therefore vital to intercede at the first signs of heat exhaustion to prevent this progression, especially in those who have underlying health conditions such as obesity, diabetes, and cardiovascular disease [5].

Firefighters have a higher than average obesity rate compared to other adults in the US, rendering the profession a key focus area for research into heat stress prevention [6,7]. Fehling et al [8] have conducted several studies to explore the relationship between heat stress and dehydration in firefighters, concluding that, when compounded together, the heart muscle's work is substantially increased while perfusion to the heart is decreased [8]. In their earlier studies, they found evidence of an increase in blood platelets after 18 minutes in burn training scenarios [3].

Laron et al found that firefighters can ward off the symptoms of heat stress by increasing their intake of fluids (2015), but case studies have demonstrated that heat-related incidents continue to occur even with aggressive fluid intake [9]. Other studies have demonstrated the effects of heat strain with only short periods (6 minutes) of work in typical firefighter personal protective equipment (PPE) [10]. In addition, long-term heat exposures without sufficient recovery time 
have produced increased levels of cortisol and interleukin- 6 , which either weaken the immune system or trigger inflammatory or autoimmune responses [11].

Solutions to the heat stress incurred by firefighters have ranged from cooling vests to immersion of hands in cold water, but neither have been shown to adequately return core temperature to normal fast enough to prevent heat-related illness [12]. A 2020 systematic review of methods to mitigate heat illness in occupational settings did, however, show that specialized cooling garments, improving aerobic fitness, immersion in cool water, and exposure to cool ventilation were the most effective measures [13].

In the absence of sound solutions, firefighters and other first responders need warning systems to alert them to the impending health hazards of heat stress. Unfortunately, several studies have attempted to correlate internal core temperature readings with skin temperature monitoring, with little to no success [14]. Even systems modeling, using air temperature, wind speed, solar load and clothing variables, fails to be a consistent predictor of the onset of heat illness [15]. The 2016 NIOSH Criteria of Recommended Standard: Occupational Exposure to Heat and Hot Environments recommends employers establish a medical monitoring system in an attempt to identify signs of heat-related illness and predict and prevent longterm adverse outcomes. The thought is heat-related illnesses may also affect the absorption of toxic chemicals, which has dire consequences for firefighters who respond to current and future hazardous materials events [16].

A 2018 study in the U.S. indicated that $23 \%$ of HAZMAT units and $39 \%$ of firefighter units had at least one case of heat-related illness in their responders in the previous year. Although $25 \%$ of all departments surveyed had no post-cooling strategies for their responders, firefighting departments were more likely to have said procedures. Cost, logistics and awareness remain the leading barriers to implementation of post-cooling methods [17].

As ambient temperatures increase through climate change, the need for early warning systems for first responders becomes increasingly important [18]. An aging workforce plagued with chronic medical conditions also increases the risk for morbidity and mortality in the line of duty [19]. It is imperative the research be aimed at identifying the early signs of heat-related health emergencies, so intervention can be swift and timely.

These research findings, among others, have dovetailed into national concerns of security and safety which have been codified into legislative action. In particular, the Fixing America's Surface Transportation Act, or "FAST Act", signed into law by President Obama on December 4, 2015, has sought to address these problems [20]. FAST Act addresses national level concerns associated with transporting hazardous materials safely and establishes requirements for real-time emergency response information and for monitoring human exposure during hazardous material incidents.

This work follows up on such studies by working with HAZMAT first responders in Nebraska to explore and assess the current status of responder safety in the state. While the broader goals of the project center on designing, developing, and testing an integrated technology prototype for safety monitoring and minimizing first responder health impacts during response scenarios, the focus of this paper is to report on the data gathered through the focus groups addressing the status of Nebraska HAZMAT response.

For the first phase of the project, several requirement gathering activities were conducted, including a literature review, interviews with key stakeholders, focus groups with first responders, a review of current sensor technology, and a research study was prepared on best practices for human health parameter data visualization on the dashboard. This paper will explore the first responder focus group requirement gathering process. A consensus building process entitled, Technology of Participation ${ }^{\circledR}$
(ToP) was used for the focus group sessions [21].

\section{Methods}

The Technology of Participation ${ }^{\circledR}$ approach is designed to involve individual members of the HAZMAT response team in the decisionmaking process of exploring perceptions. The process begins with providing context for the consensus, which in this case was to explore the facets of a HAZMAT response which elicited concern, either real or perceived, among the team members. Members do their own individual brainstorming by creating their own list of items. Small groups then share their individual lists and create a comprehensive list as a unit. All list items are then collectively viewed by all participants, followed by a clustering process to create groups of like items. Once clusters are formed, participants are asked to name the cluster as a theme for the list of items thereunder. At the conclusion of this process, the participants have created a working consensus of thematic areas of concern they experienced in the course of their responsibilities as a HAZMAT response team. The ToP method ensures individual inputs are not excluded through the natural dynamics of a hierarchical organizational structure. All responses are included in the clustering process and are not lost to dismissal by stronger and perhaps more vocal participants who may outrank their peers. The output from this consensus building and needs assessment approach provides valuable direction for the remainder of the overall project, and ensures the investment made in solutions is derived from sound exploration and is without bias [22].

Members of a HAZMAT team in Omaha, Nebraska were asked to volunteer to participate in a focus group. The study was conducted according to the guidelines of the Declaration of Helsinki and approved by the Institutional Review Board of the University of Nebraska as an Exempt Educational, Behavioral, and Social Science Research (protocol approval \#691-17-EX on November 6th, 2017). Informed consent was obtained from all subjects in the study through an email notification to participate in the focus group and no demographic information was collected to ensure anonymity. Notification was approved by University of Nebraska IRB (protocol approval \#691-17-EX on November 6th, 2017). Eight participants were present and were asked the following question: "When you are responding to a HAZMAT event, what are the things that you worry about?" Participants were then asked to make an individual list of 10 items of concern. Each item was transcribed to an individual card and placed on a workspace visible to all participants. Participants were subsequently asked to cluster together similar cards or which represented a common theme. Once clustering was complete, participants were asked to create a thematic name for each cluster. Individual cards were then removed while thematic headings remained visible. Participants were asked to brainstorm possible solutions to any concerns classified under the thematic areas and place those solutions on individual cards under the appropriate heading.

\section{Results}

Table 1 represents the clusters of items HAZMAT responders considered as concerns when they respond to an event. Thematic areas include: Responder Safety; Training; Risk Assessment; Incident Command; Personal Protective Equipment; Weather and Location; Communication; Hazard/Product Identification; Public Safety and Post Incident Review. Each item under "Concerns" represents an individual card placed by all participants. The majority of concerns $(23 \%)$ were classified as related to responder safety. The concerns range from individual consequences such as the short-term effects of hazards from either poor responder tracking or exposure to the hazardous material, to the longer-term effects of repeated exposures, including the potential secondary exposure effects on family members. 


\begin{tabular}{|c|c|c|}
\hline Themes & \multicolumn{2}{|c|}{ Concerns } \\
\hline \multirow[t]{6}{*}{ Responder Safety } & Safety of responders & Life safety \\
\hline & Fire fighter accountability & Respondent exposure \\
\hline & Potential external hazards & Long-term health effects \\
\hline & Adequate staffing? & $\begin{array}{l}\text { Education/awareness of } \\
\text { political level }\end{array}$ \\
\hline & Exit strategy if things go bad & Taking home to family \\
\hline & $\begin{array}{l}\text { Incident stabilization/property } \\
\text { conservation }\end{array}$ & \\
\hline \multirow[t]{2}{*}{ Training } & Sufficient training & Proper equipment/tools \\
\hline & Previous incident experience & \\
\hline \multirow[t]{2}{*}{ Risk Assessment } & Secondary Explosions & \\
\hline & Bioterrorism & \\
\hline \multirow[t]{2}{*}{ Incident Command } & Subject matter expert available? & \\
\hline & $\begin{array}{l}\text { Will proper procedures } \\
\text { be followed by incident } \\
\text { commander? }\end{array}$ & \\
\hline \multirow[t]{2}{*}{$\overline{\mathrm{PPE}}$} & $\begin{array}{l}\text { Adequate PPE/ Proper/correct } \\
\text { PPE }\end{array}$ & Extra resources \\
\hline & Can't see & Maintenance and equipment \\
\hline \multirow[t]{2}{*}{ Weather and Location } & $\begin{array}{l}\text { Exact location of spill/leak; } \\
\text { topography }\end{array}$ & \\
\hline & Weather conditions & \\
\hline \multirow[t]{2}{*}{ Communication } & $\begin{array}{l}\text { Communication to the } \\
\text { community }\end{array}$ & $\begin{array}{l}\text { Information collection and } \\
\text { dissemination }\end{array}$ \\
\hline & $\begin{array}{l}\text { Communication among } \\
\text { responders (own unit) and } \\
\text { interagency }\end{array}$ & $\begin{array}{l}\text { Communication before we get } \\
\text { to the scene }\end{array}$ \\
\hline \multirow[t]{2}{*}{ Hazard/Product Identification } & Building layout/incident layout & Data gathering \\
\hline & Equipment working? & $\begin{array}{l}\text { How/what will HAZMAT } \\
\text { change? }\end{array}$ \\
\hline \multirow[t]{3}{*}{ Public Safety } & Evacuate vs shelter & $\begin{array}{l}\text { Notify and evacuate potential } \\
\text { victims }\end{array}$ \\
\hline & Where can HAZMAT go? & $\begin{array}{l}\text { How many have been exposed } \\
\text { potential victims? }\end{array}$ \\
\hline & Property conservation & Safety of citizens/public \\
\hline \multirow[t]{2}{*}{ Post Incident Review } & Interagency results and findings & $\begin{array}{l}\text { What to do differently next } \\
\text { time }\end{array}$ \\
\hline & Lessons learned & What worked/what did not \\
\hline
\end{tabular}

Table 1: Station X - HAZMAT Focus Group for Needs Assessment Results 
Figure 1 represents the brainstormed solutions to the items of concern clustered under the thematic area entitled: Responder Safety. Each orange box represents an individual concern/challenge from the cards generated by participants for the Responder Safety thematic area. Each box contains a list of proposed solutions to the specific challenge/concern.
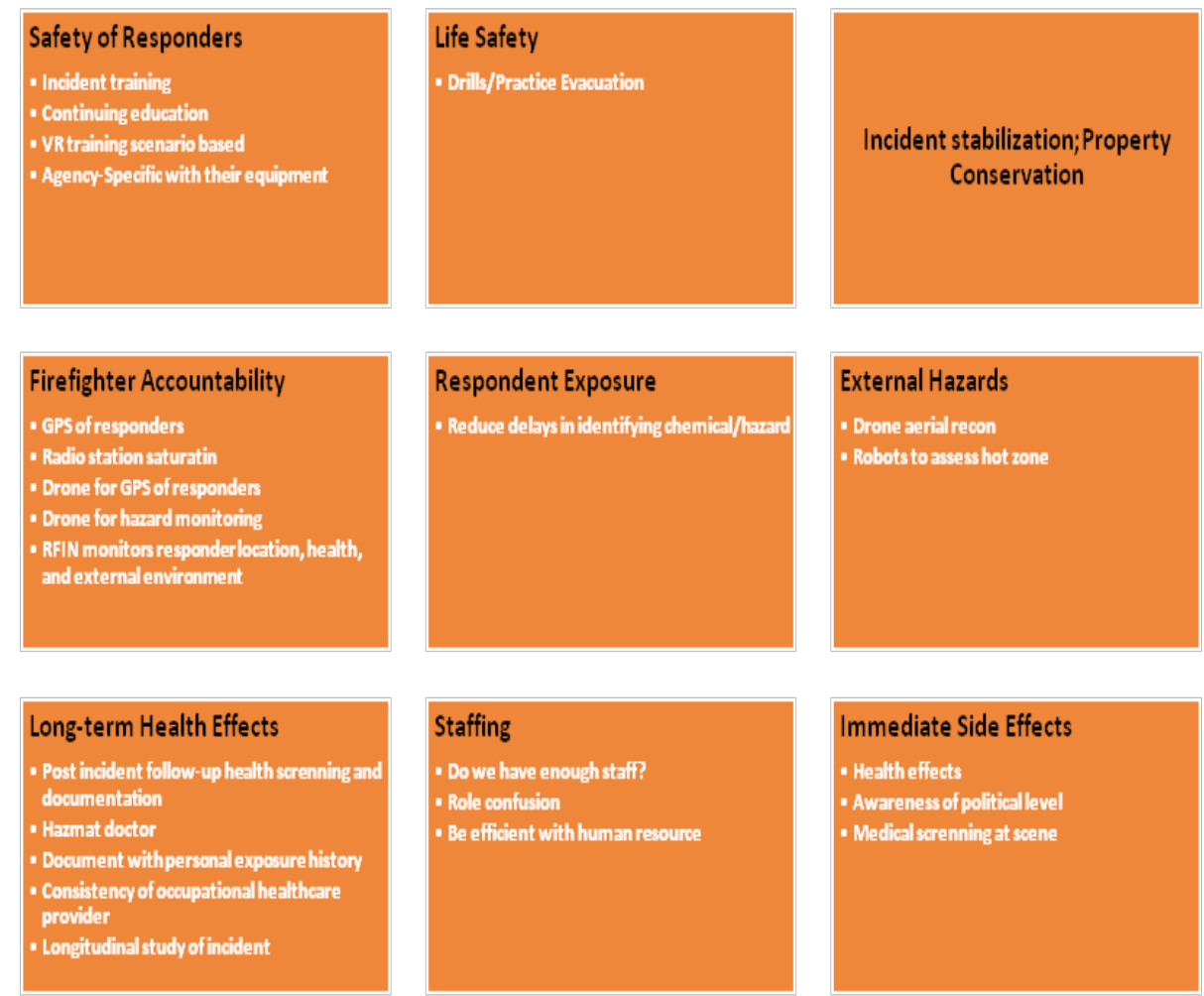
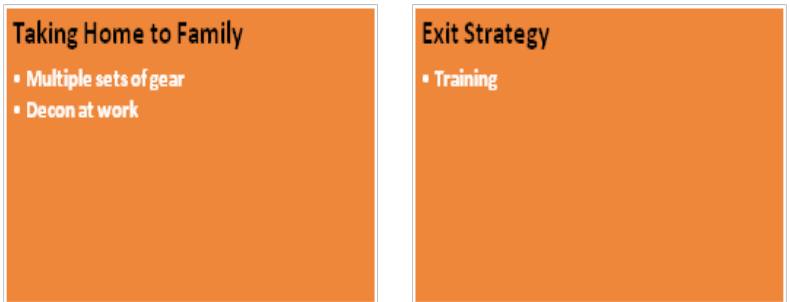

Figure 1: Solutions to items of concern

\section{Discussion}

Although we recognize the limitations of a small sample size in this focus group, we also appreciate the value of a consensus process that produces perceptions often reflected in the literature. With large rural populations across the country reliant on volunteer response forces, targeted interventions will be key to alleviating responder concerns.

The focus group participants attributed some safety concerns to lack of training and suggested increased training, drills and exercises to address these gaps. Incorporation of simulation technology such as virtual reality was proposed, perhaps a signal to generational differences and a preference for more interactive and technologically advanced modes of instruction. Virtual reality has been used pedagogically in training first responders to responses which include fuel cell and hydrogen technologies transported in Europe. In keeping with adult learner principles that ascribe to more problem-centered rather than content-centered curriculum, virtual reality offers an immersive experience into a mock scenario and tests the responder's ability to make decisions based on the specific event [23]. Rural communities have also turned to simulation-based training techniques to ensure first responders in remote areas have equal access to training and have demonstrated high levels of learner satisfaction in the process [24].
Ascertaining the exact location of responders in a chaotic response was also listed as a concern of the focus group participants. Direct questions to team commanders confirmed this concern. Incident commanders expressed the desire for better responder accountability technology, and ideas for solutions were mostly based on new innovative technology. Drones were suggested by several focus group members, despite public concerns for privacy regarding the use of drones, and first responders have been using drones in Canada and the US more frequently in the last 10 years [25]. Among other things, drones have been used to assess the scene, communicate from the command post to responders and/or victims at the scene, transport medical supplies, and place sensors for wireless communication in a disaster [26, 27].

Short-term and long-term health effects from exposure to hazardous materials are common concerns for the participants of this focus group and were reflected in the solutions gathering phase. Participants thought immediate health screening at the scene could alleviate some of the health effects but were not specific about how it would be accomplished. Data on acute chemical injuries to first responders from across the country shed light on the issue at a national level. From 2002-2012, there were sufficient injuries and exposures to warrant an in-depth analysis [28]. Most immediate adverse events were 
actually due to human error or equipment failure. Firefighters who wore personal protective equipment (PPE) either chose not to wear respiratory protection during the fire or to remove it after the flames were extinguished, exposing themselves to harmful chemicals in both cases. Some cited difficulties with communications as the reason, and others thought masks were no longer necessary once the fire was extinguished. A greater risk for firefighters comes with the inherent use of proper PPE. The incidents of acute and at times dangerous health events related to heat and cardiovascular stress far outnumber those involving the exposure to chemicals, given credence to the ongoing need to improve personal protective technology [28]. Other studies have demonstrated first responders don a lower level of PPE to limit the ergonomic and dexterity restraints of a fully protective ensemble [29]. Medical screening on scene may accelerate the timeline procedures for cooling the first responders and monitoring as they come directly from the scene, but better compliance with the highest protection of PPE and instituting strict time limitations while in PPE may be a more appropriate role for medical monitoring personnel. Identification of the hazardous materials becomes less important if first responders are protected to the highest level for the most dangerous exposure and are monitored for the health effects of the PPE rather than for the environmental dangers they combat.

Monitoring of the long-term health effects of the profession is more challenging. The National Institute for Occupational Safety and Health (NIOSH) implemented an Emergency Responder Health Monitoring and Surveillance (ERHMS) system in the last decade to conduct onscene and post-event monitoring for first responders responding to a disaster. The goal of this program is to ensure workers maintain their ability to respond effectively and are not harmed during response work, and to identify exposures early in the course of an emergency response to prevent or mitigate adverse physical and psychological outcomes [30]. A standardized program like ERHMS does not exist for responses to emergencies which do not rise to the level of a disaster or public health emergency. Professional first responders must rely on their organizations to be proactive and perform immediate and longterm monitoring. Although this study targeted only one HAZMAT team setting and may not be generalizable to all, these focus group participants made suggestions for strategies to attain longer term health tracking that range from the establishment of a documentation system for longitudinal monitoring to recommending consistency in occupational health services providers, demonstrating the value of this focus group study to impact the lives of our first responder population going forward.

\section{Conclusion}

First responders to incidents involving hazardous materials work tirelessly in pursuit of public safety. They belong to a profession with documented risks and adverse outcomes as a direct result of their job, and the equipment they use to protect themselves from the hazards. Heat stress and cardiac events top the list of adverse health threats, but long-term sequalae are also documented in the few longitudinal studies that have been conducted [31]. Responders from an Omaha area HAZMAT team were able to articulate their concerns in a focus group setting using a systematic facilitation process. They voiced concerns for their health and safety in the short-term and in the long-term; at the same time, they acknowledged the dearth of responder monitoring at the scene or over time. The results of this focus group serve to inform researchers of priorities to consider in the development of responder health monitoring systems and to continue with research in wearable technology for real-time health monitoring. Early intervention when monitored responders demonstrate signs of distress ultimately saves lives in the short-term, but also provides data to be analyzed over the long-term. In the absence of resourceintensive health monitoring by practitioners, wearable sensors may be the answer to systematic health monitoring of first responders and early warning to scene commanders for intervention strategies. The future of responder health and safety using sensors should be explored as a solution to reported adverse events and responder concerns. Wearable technology and sound user interface technology for monitoring may be the future solution for today's gaps in responder health surveillance.

Competing Interests: The authors declare no competing interests.

Acknowledgments: Authors wish to acknowledge the Omaha Fire Department and specifically Station 33 HAZMAT team leadership and members for their collaboration in this focus group study. This work would not be possible without funding from the US Department of Transportation and their support of the Mid-America Transportation Center at the University of Nebraska.

\section{Reference}

1. Lasisi, A., Bai, L., \& Sun, Z. (2012). An Empirical Study on Risk Mitigation in Transporting Hazardous Material. Paper presented at the IIE Annual Conference. Proceedings.

2. Incident Statistics. (2021). Retrieved from https://portal.phmsa. dot.gov/analytics/saw.dll?PortalPages

3. Smith, D., L, Horn, G., Goldstein, E., Petruzzello, S., J, Brauer, B., Fernhall, B., ... Woods, J. (2008). Firefighter Fatalities and Injuries The role of heat stress and PPE. Retrieved from

4. Arbury, S., Jacklitsch, B., Farquah, O., Hodgson, M., Lamson, G., Martin, H., \& Profitt, A. (2014). Heat Illness and Death among Workers United States, 2012-2013. Retrieved from

5. Pillai, S. K., Noe, R. S., Murphy, M. W., Vaidyanathan, A., Young, R., Kieszak, S., . . . Lewis, L. (2014). Heat illness: Predictors of hospital admissions among emergency department visits-Georgia, 2002-2008. Journal of community health, 39(1), 90-98.

6. Jahnke, S., Poston, W., Haddock, C., \& Jitnarin, N. (2013). Obesity and incident injury among career firefighters in the central United States. Obesity, 21(8), 1505-1508.

7. Tsismenakis, A. J., Christophi, C. A., Burress, J. W., Kinney, A. M., Kim, M., \& Kales, S. N. (2009). The obesity epidemic and future emergency responders. Obesity, 17(8), 1648-1650.

8. Fehling, P., Haller, J., Lefferts, W., Hultquist, E., Wharton, M., Rowland, T., \& Smith, D. (2015). Effect of exercise, heat stress and dehydration on myocardial performance. Occupational Medicine, 65(4), 317-323.

9. Cuddy, J., S., \& Ruby, B., C. (2011). High Work Output Combined with High Ambient Temp Caused Heat Exhaustion in a Wildland Firefighter despite high fluid intake. Wilderness \& Environmental Medicine, 22, 122-125.

10. Petruzzello, S. J., Gapin, J. I., Snook, E., \& Smith, D. L. (2009). Perceptual and physiological heat strain: examination in firefighters in laboratory- and field-based studies. Ergonomics, 52(6), 747-754. doi:10.1080/00140130802550216

11. Watt, P. W., Willmott, A. G., Maxwell, N. S., Smeeton, N. J., Watt, E., \& Richardson, A. J. (2016). Physiological and psychological responses in Fire Instructors to heat exposures. Journal of thermal biology, 58, 106-114.

12. Carter, J., Rayson, M., Wilkinson, D., Richmond, V., \& Blacker, S. (2007). Strategies to combat heat strain during and after firefighting. Journal of thermal biology, 32(2), 109-116.

13. Morris, N. B., Jay, O., Flouris, A. D., Casanueva, A., Gao, C., Foster, J., . . Nybo, L. (2020). Sustainable solutions to mitigate occupational heat strain-an umbrella review of physiological effects and global health perspectives. Environmental Health, 19(1), 1-24. 
14. Pryor, R. R., Seitz, J. R., Morley, J., Suyama, J., Guyette, F. X., Reis, S. E., \& Hostler, D. (2012). Estimating core temperature with external devices after exertional heat stress in thermal protective clothing. Prehospital Emergency Care, 16(1), 136141.

15. Yokota, M., Berglund, L. G., Santee, W. R., Buller, M. J., Karis, A. J., Roberts, W. S., . . Hoyt, R. W. (2012). Applications of real-time thermoregulatory models to occupational heat stress: validation with military and civilian field studies. The Journal of Strength \& Conditioning Research, 26, S37-S44.

16. Jacklitsch, B., Williams, J., Musolin, K., Coca, A., Kim, J.-H., \& Turner, N. (2016). Criteria for a recommended standard: occupational exposure to heat and hot environments. NIOSH Publ.

17. Bach, A. J. E., Maley, M. J., Minett, G. M., \& Stewart, I. B. (2018). Occupational cooling practices of emergency first responders in the United States: A survey. Temperature (Austin), 5(4), 348-358. doi:10.1080/23328940.2018.1493907

18. Williams, A. A., Allen, J. G., Catalano, P. J., Buonocore, J. J., \& Spengler, J. D. (2020). The Influence of Heat on Daily Police, Medical, and Fire Dispatches in Boston, Massachusetts: Relative Risk and Time-Series Analyses. Am J Public Health, 110(5), 662-668. doi:10.2105/ajph.2019.305563

19. White, M. S., Burns, C., \& Conlon, H. A. (2018). The Impact of an Aging Population in the Workplace. Workplace Health Saf, 66(10), 493-498. doi:10.1177/2165079917752191

20. Act, F. (2015). Fixing America's Surface Transportation Act. Paper presented at the 114th Congress of the United States of America, January.

21. Umpleby, S., Medvedeva, T., \& Oyler, A. (2004). The technology of participation as a means of improving universities in transitional economies. World Futures: The Journal of General Evolution, 60(1-2), 129-136.

22. Stanfield, R. B. (2002). The workshop book: From individual creativity to group action: New Society Publishers.
23. Tretsiakova-McNally, S., Maranne, E., Verbecke, F., \& Molkov, V. (2017). Mixed e-learning and virtual reality pedagogical approach for innovative hydrogen safety training of first responders. International Journal of Hydrogen Energy, 42(11), 7504-7512.

24. Martin, D., Bekiaris, B., \& Hansen, G. (2017). Mobile emergency simulation training for rural health providers. Rural and remote health, 17(4057).

25. Khan, M. N. H., \& Neustaedter, C. (2019a). An Exploratory Study of the Use of Drones for Assisting Firefighters During Emergency Situations. Paper presented at the Proceedings of the 2019 CHI Conference on Human Factors in Computing Systems.

26. Graven, O. H., Bj, J., Samuelsen, D. A. H., \& Bjerknes, J. D. (2017). Managing disasters-rapid deployment of sensor network from drones: Providing first responders with vital information. Paper presented at the 2017 2nd International Conference on Control and Robotics Engineering (ICCRE).

27. Khan, M. N. H., \& Neustaedter, C. (2019b). Exploring Drones to Assist Firefighters During Emergencies.

28. Melnikova, N., Wu, J., Yang, A., \& Orr, M. (2018). Acute chemical incidents with injured first responders, 2002-2012. Disaster medicine and public health preparedness, 12(2), 211221.

29. Elston, H. J., \& Perrero, D. (2019). Looking at the bigger picture: Evaluating responder risk in a tritium spill. Journal of Chemical Health and Safety.

30. Funk, R. H. (2018). Applications: Emergency Responder Health Monitoring and Surveillance: Successful Application. In Disaster Epidemiology (pp. 121-128): Elsevier.

31. Tuminello, S., van Gerwen, M. A., Genden, E., Crane, M., Lieberman-Cribbin, W., \& Taioli, E. (2019). Increased incidence of thyroid cancer among World Trade Center first responders: A descriptive epidemiological assessment. International journal of environmental research and public health, 16(7), 1258. 